\title{
Geonomic assessment of white clover and perennial ryegrass genetic resources
}

\author{
Marty J. FAVILLE ${ }^{1, *}$ Andrew G. GRIFFITHS ${ }^{1}$, Abdul BATEN ${ }^{1}$, Mingshu CAO $^{1}$, Rachael ASHBY ${ }^{2}$, Kioumars \\ GHAMKHAR $^{1}$, Won HONG ${ }^{1}$, Anna LARKING ${ }^{1}$, Michelle WILLIAMSON ${ }^{1}$ and Zane WEBBER ${ }^{1}$ \\ ${ }^{1}$ AgResearch, Grasslands Research Centre, Private Bag 11008, Palmerston North, New Zealand \\ ${ }^{2}$ AgResearch, Invermay Agricultural Centre, Private Bag 50034, Mosgiel, New Zealand \\ *Corresponding author: marty.faville@agresearch.co.nz
}

\begin{abstract}
Forage resources conserved in genebanks, such as the Margot Forde Germplasm Centre (MFGC; Palmerston North), are reservoirs of genetic diversity important for the development of cultivars adapted to abiotic stresses and environmental constraints. Genomic tools, including genotyping-by-sequencing (GBS), can support identification of manageable subsets (core collections) that are genetically representative of these large germplasm collections, for phenotypic characterisation. We used GBS to generate SNP (single nucleotide polymorphism) profiles for 172 white clover (WC) and 357 perennial ryegrass (PRG) MFGCsourced accessions and estimated genetic relationships amongst accessions. In WC, accessions aligned along an east-west transect from Kazakhstan to Spain, identifying major diversity in Caucasus/Central Asia and Iberian Peninsula. A key feature was the reduced diversity present in New Zealand (NZL) accessions. Similarly, for PRG, most NZL accessions coalesced as one group, distinct from large clusters associated with the Iberian Peninsula, Italy and eastern Mediterranean/ Caucasian region. These results emphasise the relatively narrow genetic diversity in NZL WC and PRG, and the broad extent of largely unexploited global diversity. Capturing global genetic variation in core collections will support pre-breeding programmes to mobilise novel genetic variation into New Zealandadapted genetic backgrounds, enabling development of cultivars with non-traditional traits including enhanced climate resilience and environmental performance.
\end{abstract}

Keywords: core collection, Lolium, genetic diversity, genotyping-by-sequencing, Trifolium

\section{Introduction}

The importance of perennial ryegrass (Lolium perenne L.; PRG) and white clover (Trifolium repens L.; WC) in mixed swards as a source of nutrition for ruminant livestock grazed on New Zealand farms, is well recognised and is of particular consequence in the dairy sector (Chapman et al. 2017). Interest in a range of other forage species (including plantain, chicory, tall fescue, cocksfoot, red clover and subterranean clover) within New Zealand's pastoral systems has increased in recent years but ryegrass and clover species still rank as the country's most economically significant plant species, together contributing nearly NZ\$17B to annual GDP (Ministry for Primary Industries 2016). The major focus for genetic improvement in these species has been enhancement of annual and seasonal herbage yield (Lee et al. 2012) with less focus on other traits such as nutritive quality, seed yield, disease and pest resistance, symbiont compatibility and vegetative persistence (Easton et al. 2002; Widdup et al. 2004; Williams et al. 2007; Lee et al. 2012). Significant performance gains for yield have been achieved through breeding (Woodfield \& Easton 2004; Lee et al. 2012; Harmer et al. 2016; Hoyos-Villegas et al. 2019) based on utilisation of genetic diversity within New Zealandadapted germplasm, supplemented as required by globally sourced introductions (for example, perennial ryegrass from north-western regions of Spain) (Stewart 2006).

Emerging pastoral sector priorities (Anonymous 2017; Ministry for Primary Industries 2017) indicate a shift in focus beyond productivity per se, targeting greater climate resilience, including improved response to soil moisture deficit, and towards developing forage cultivars that are better adapted for environmentally sustainable production, for example by means of reduced nitrogen and phosphorous fertiliser requirements. For PRG and WC, an important approach for addressing these and other novel traits will be to explore beyond the genetic diversity available locally by systematically characterising and then utilising germplasm sourced from other countries. A genetic analysis of natural populations across Europe by Blanco-Pastor et al. (2019) revealed a broad range of genetic variation available for use in PRG breeding. In the same study, modern cultivars (including cultivars bred in New Zealand) were found to be principally derived from just one of the seven major genetic groups identified by the analysis. This finding suggests that there are large pools of PRG genetic variation that are under-utilised, and which may contain valuable alleles.

As noted by Stewart (2006), overseas germplasm sources potentially possess useful, novel genetic 
variation that can be introduced by crossing into locally adapted material. An example of this, mentioned above, is the introduction of late-flowering and higher winteractivity traits into New Zealand PRG cultivars, using germplasm sourced from north-western Spain. Further afield, ryegrass cultivars bred to express elevated water-soluble carbohydrate in leaves were based on ecotype material collected in the Zurich uplands of Switzerland (Humphreys 1989). Finally, the grazingtolerant, persistent New Zealand red-clover variety "Grasslands Relish" (Ford \& Barrett 2011) was the result of a breeding programme that integrated novel genetics from globally sourced ecotypes into New Zealand-adapted germplasm (Pers. comm, Mr John Ford, PGG Wrightson Seeds Ltd.).

Global genetic resources conserved in genebanks, such as the Margot Forde Germplasm Centre (MFGC) in Palmerston North, New Zealand, are locally accessible reservoirs of extensive genetic diversity. However, an effective analysis of traits across the full collection is impractical given that the MFGC alone currently contains approximately 2,700 PRG and 3,900 $\mathrm{WC}$ accessions (accession $=$ a sample of seed collected from a population or family). One approach to enable systematic characterisation of these large resources is to first extract a smaller 'core collection' for the species and to focus subsequent efforts on assessing traits using this stratified sample. A core collection is a manageable subsample of the accessions in the genebank collection that contains, a minimum "optimum" number of entries representing the spectrum of genetic diversity for the species (Frankel 1984). Various sampling strategies are used to guide the assemblage of plant core collections and these often involve a process of hierarchical stratification (Brown 1989), whereby accessions are first grouped together based on similarity of characters, including geographical location, ecological and climatic parameters and, if available, agro-morphological data. Accessions can then be selected from within these groups to assemble the core collection.

Molecular markers are regarded as the most reliable source of qualitative data for supporting core collection design (Ghamkhar et al.2008) and are useful for different sampling strategies. Genotyping-by-sequencing (GBS) (Elshire et al. 2011) is a method for generating high numbers of single nucleotide polymorphism (SNP) molecular markers for any species, and has been recently established for both PRG and WC (Faville et al. 2018; Griffiths et al. 2019). This marker platform is highly efficient and cost-effective with diverse applications in biology, including analysis of genetic diversity. Furthermore, GBS can be applied to DNA samples pooled from numerous individuals within a population (pool-GBS) (Byrne et al. 2013). A pooling approach enables greater efficiency when capturing genetic information from large numbers of populations (Blanco-Pastor et al. 2019), particularly for outbreeding species such as WC and PRG, which exhibit high levels of diversity. This is because genetic variation within a population is typically high for these species, (Bolaric et al. 2005; Khanlou et al. 2011; Faville et al. 2020). In order to sample the overall within-population genetic diversity of the population, random samples of over 20 individuals are recommended (Kubik et al. 2001; Khanlou et al. 2011).

Little is known about genetic diversity amongst New Zealand's locally adapted PRG and WC populations. The objective of this study was to characterise, using pool-GBS technology, the genetic diversity amongst WC and PRG MFGC accessions pre-selected based on eco-geographic data, as a first step towards development of core collection resources. Focus was placed on developing improved understanding of the global genetic diversity present in these species as it relates to genetic diversity represented in New Zealandadapted populations and cultivars.

\section{Materials and Methods}

\section{Plant material and DNA isolation}

Based on an earlier ecogeographical filtering (Dr Kioumars Ghamkhar, unpublished data) of 4200 WC and 5267 PRG New Zealand and globally sourced accessions using MSTRAT software (Gouesnard et al. 2001), $203 \mathrm{WC}$ accessions and 357 PRG were selected for GBS analysis. Seed for these were acquired from the Margot Forde Germplasm Centre (MFGC), Palmerston North, New Zealand (Table 1). A full list of the accessions selected is provided in Additional File 1. Entries in the MFGC database for eight of the PRG accessions used were noted as having a high seed awn frequency or potentially of "annual/hybrid" origin. For PRG, an additional five New Zealand cultivars ('Nui', 'Ruanui', 'One50', 'Impact' and 'Samson') were added to the analysis. Approximately $0.03 \mathrm{~g}$ of seed per WC accession was scarified with sandpaper, moistened on filter paper in Petri dishes, incubated at $4^{\circ} \mathrm{C}$ for a minimum of 48 hours, then placed at room temperature to germinate. Seedlings were transplanted into commercial seed-raising mix in 100-cell seed trays and grown in a greenhouse until sufficient leaf material was available for DNA extraction. A similar protocol was followed for PRG, except that approximately $0.1 \mathrm{~g}$ of seed per accession was sown directly into seed-raising mix in trays. For a small number of older accessions, pre-treatment of seed was conducted as described for white clover, to achieve germination.

For WC, one trifoliate leaf was sampled from each of 30 plants per accession, with care taken to sample similar sized leaves, and placed into a single bag. Leaf material was freeze-dried then ground to a fine powder 
Table 1 Geographical sources of white clover (WC) and perennial ryegrass (PRG) accessions used for genotyping-by-sequencing (GBS) analysis.

\begin{tabular}{|c|c|c|}
\hline Source & $\begin{array}{c}\text { No. WC } \\
\text { accessions }\end{array}$ & $\begin{array}{c}\text { No. PRG } \\
\text { accessions }\end{array}$ \\
\hline Afghanistan (AFG) & - & 2 \\
\hline Armenia (ARM) & 5 & 12 \\
\hline Australia (AUS) & 5 & - \\
\hline Azerbaijan (AZE) & 5 & - \\
\hline Canada (CAN) & 6 & - \\
\hline Costa Rica (COS) & 2 & - \\
\hline Cyprus (CYP) & - & 8 \\
\hline Denmark (DEN) & - & 1 \\
\hline France (FRA) & 2 & 2 \\
\hline Georgia (GEO) & 11 & 24 \\
\hline Greece (GRE) & 2 & 26 \\
\hline Iran (IRA) & - & 1 \\
\hline Italy (ITA) & 14 & 22 \\
\hline Kazakhstan (KAZ) & 5 & - \\
\hline Monaco (MON) & - & 1 \\
\hline Morocco (MOR) & - & 3 \\
\hline New Zealand (NZL) & $63^{1}$ & $119^{2}$ \\
\hline Norway (NOR) & - & 1 \\
\hline Portugal (POR) & 22 & 22 \\
\hline Russia (RUS) & 6 & - \\
\hline South Africa (SAF) & - & 1 \\
\hline Spain (SPN) & 20 & 63 \\
\hline Tajikistan (TAJ) & 6 & 6 \\
\hline Tunisia (TUN) & - & 2 \\
\hline Turkey (TUR) & 13 & 40 \\
\hline United Kingdom (GBR) & 1 & - \\
\hline United States of America (USA) & 15 & 1 \\
\hline Total & 203 & 357 \\
\hline
\end{tabular}

1 WC accessions from : Northland $(n=6)$, Auckland (1), East Coast (1), Hawke's Bay (9), King Country (1), Wanganui (3), Manawatu (2), Wairarapa (14), Marlborough (4), Canterbury (8), Otago (5) and Southland (9)

2 PRG accessions from: Auckland $(n=1)$, Waikato (14), Bay of Plenty (14), Central Plateau (1), East Coast (7), Hawke's Bay (3), King Country (7), Taranaki (7), Rangitikei (10), Wairarapa (2), Westland (13), Canterbury (7), Otago (5), Southland (28)

in a $15 \mathrm{~mL}$ polycarbonate vial (Spex, Metuchen, NJ, USA) with a stainless-steel grinding ball (Spex) using a Geno/Grinder ${ }^{\circledR}$ (Spex). DNA isolations were conducted following the method of (Anderson et al. 2018), which contains details of buffer compositions used. DNA was extracted from $60 \mathrm{mg}$ of the bulked sample powder, which was placed into a $5-\mathrm{mL}$ tube with $2 \mathrm{~mL}$ of homogenisation buffer (HB) containing Proteinase K (Anderson et al. 2018). This was mixed and centrifuged at $4000 \mathrm{~g}$ for $10 \mathrm{~min}$. Four replicate
DNA extractions were made from each sample by transferring $300 \mu \mathrm{L}$ of supernatant to each of four wells in an Axygen 96-well $1.1 \mathrm{~mL}$ plate (Corning, NY, USA), followed by $300 \mu \mathrm{L}$ of precipitation buffer (PB). Completion of the extraction protocol was as described by Anderson et al. (2018). For PRG, a similar process was undertaken, with $50-100 \mathrm{mg}$ of pseudostem tissue harvested from each of 30 plants per accession. After freeze-drying, the bulked samples were homogenised to fine powder using a TissueLyser II (Qiagen, Venlo, The Netherlands) with two stainless steel balls and the powder was transferred to a 2-mL screw-cap tube with $1.6 \mathrm{~mL}$ of HB containing Proteinase K. Subsequent extraction steps were as described for WC, with four extractions also completed from each sample. For both species, DNA was quantified and quality checked as previously described (Anderson et al. 2018).

\section{Genotyping-by-sequencing (GBS) and genetic analysis}

Methods for GBS library development and sequencing were as described in Faville et al. (2018) for PRG and Griffiths et al. (2019) for WC, except that different restriction enzymes were used in the digestion step: PstI-MspI double digest for PRG (Poland et al. 2012) and PstI for WC. Briefly, 96-plex GBS libraries were generated for each of four replicate DNA extracts per bulk sample and each library was sequenced on two lanes of an Illumina HiSeq 2500 (Illumina, San Diego, CA, USA) at AgResearch Invermay, New Zealand.

For PRG, TASSEL software (ver 5.2.54) (Glaubitz et al. 2014) was used for SNP-calling from GBS data as detailed previously (Faville et al. 2018). Filters were applied where SNPs with maximum missing per site $>50 \%$, minor allele frequency $(\mathrm{MAF})<0.05$ and averaged read depth per site $<5$ were removed. The median average of MAFs among the four replicate pools was taken and used to compute a genomic relationship matrix (GRM) based on Ashraf et al. (2014). For WC, data were quality checked, demultiplexed and mapped to the WC reference genome as described (Griffiths et al. 2019). SNPs were then identified using Stacks (Catchen et al. 2013) (ref_map.pl v. 1.47) with parameters (-S -m 3 -T 20 -b 1) and filtered as described for PRG with the addition that individuals with $>50 \%$ missing data were removed. A GRM was constructed using KGD (Dodds et al. 2015). For both datasets, hierarchical clustering (based on Euclidean distance, using average linkage clustering) was performed from the GRM and visualised as a dendrogram using the $\mathrm{R}$ package ape (Paradis \& Schliep 2018).

\section{Results and Discussion}

The goal of this study was to use GBS to investigate the genetic diversity of New Zealand-adapted white clover 
(WC) and perennial ryegrass (PRG) genetic resources, principally historical collections from pastures, within the broader context of the global diversity for these two critical forage species. Biosecurity restrictions on MFGC operations at the time of study constrained evaluations to material not subject to post-entry quarantine conditions. This limitation excluded access to germplasm sourced from some countries. Nevertheless, $67-69 \%$ of accessions examined were sourced from naturalised or wild sites outside of New Zealand, including 19 countries for PRG and 17 for WC (Table 1). Within the New Zealand-sourced germplasm, PRG accessions encompassed pastures sampled across 14 regions, from Auckland to Southland (Table 1). For WC, the analysed New Zealand (NZL) accessions were sourced from 12 regions between Northland and Southland (Table 1), with one third of them part of an historical collection made from dryland pastures (Woodfield \& Caradus 1987).

In this study, a pooled GBS strategy (Byrne et al. 2013; Blanco-Pastor et al. 2019) was used whereby tissue from 30 individuals of each accession was combined in a single tube for DNA extraction and subsequent GBS. This approach facilitated a balance of cost and diversity capture within each accession and enabled efficient capture of genetic information from only 560 DNA extractions (203 WC; 357 PRG) and 2,240 GBS assays (560 samples $\mathrm{x}$ four replicates). By contrast, assaying 30 individuals per accession separately would have required a total of 16,800 DNA extractions and GBS assays, which would have been both labour- and cost-prohibitive.

After quality filtering, GBS generated 11,157 and 150,088 single nucleotide polymorphism (SNP) markers for $203 \mathrm{WC}$ and 357 PRG accessions, respectively. Thirty-one WC accessions from across the sample set were subsequently excluded due to genotype missing rate $>50 \%$, resulting in a final dataset of 172 accessions. Dendrograms (trees representing genetic relationships) based on pairwise Euclidean distances estimated using SNP data identified patterns of genetic diversity strongly associated with geographical origin, in both species (Figures 1 and 2).

Genetic analysis of WC SNP variation aligned accessions along an east-west transect from a large cluster (V) comprising material from Central Asia (KAZ, TAJ), the Caucasus region, TUR and GRE, to a distinct Iberian peninsula (POR, SPN) genetic cluster (IV), then on to a series of related mixed clusters comprising European accessions and those

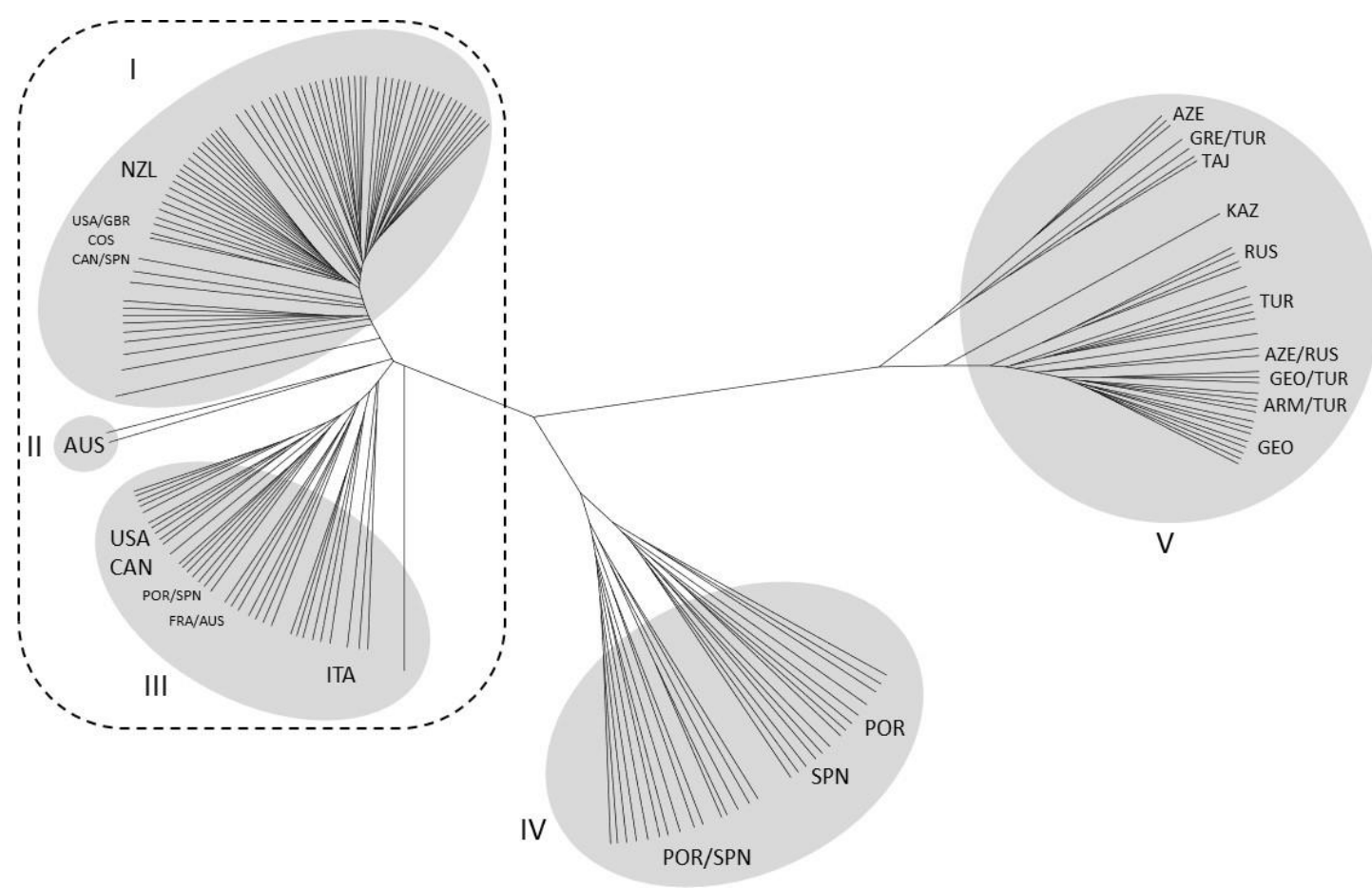

Figure 1 Dendrogram showing genetic relationships amongst 172 white clover accessions, based on Euclidean distance estimated using 11,257 GBS SNP markers. Abbreviations for country names are as per Table 1. Large font indicates the country predominantly represented in the cluster, with smaller font showing minor accessions. Clusters are labelled I to $\mathrm{V}$, and the rounded rectangle identifies related clusters of accessions derived predominantly from temperate agricultural systems in the Americas and Australasia. 


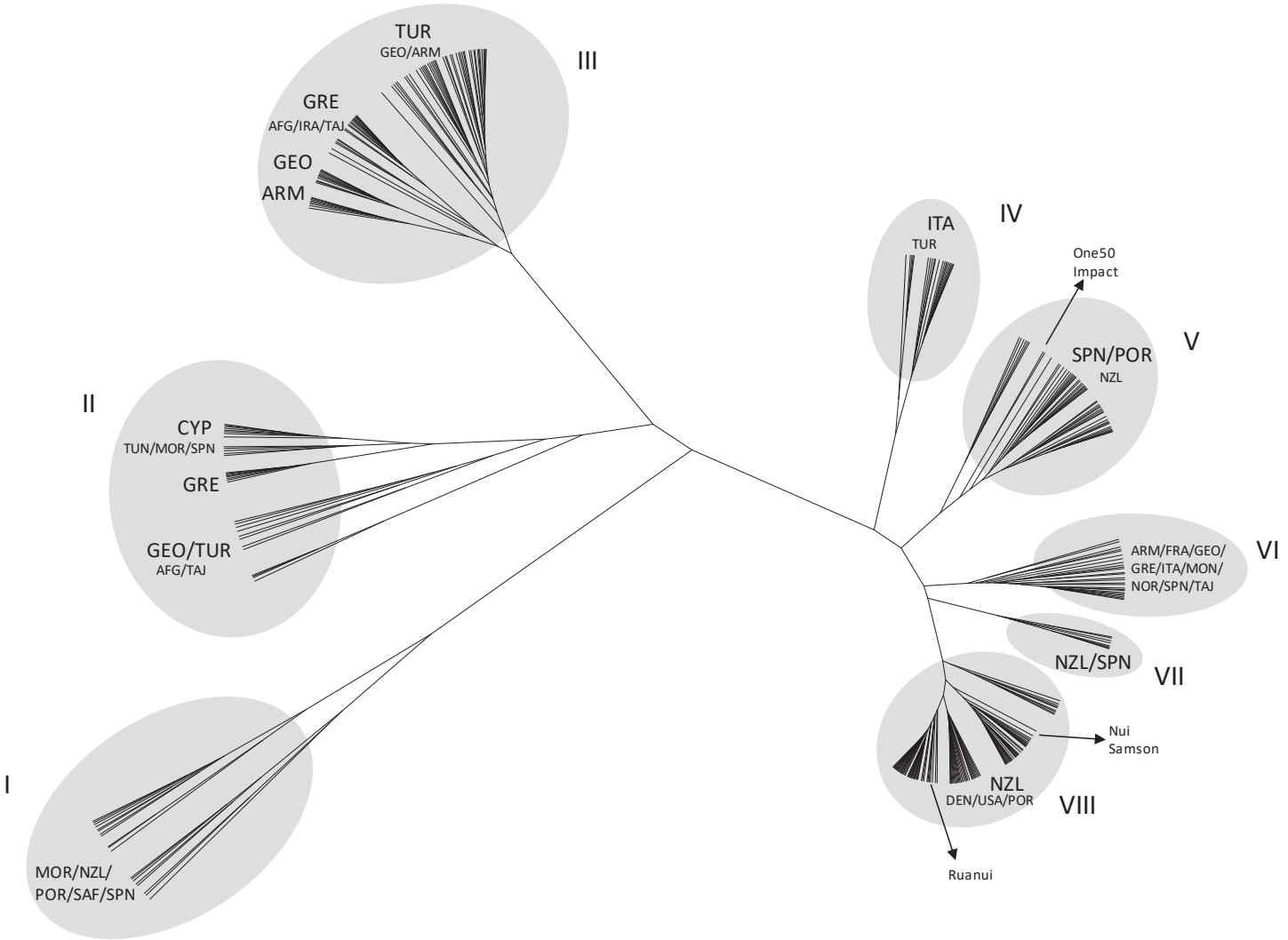

Figure 2 Dendrogram showing genetic relationships among 357 perennial ryegrass accessions and five cultivars ('One50', 'Samson', 'Impact', 'Nui' and 'Ruanui'), based on Euclidean distance estimated from 150,088 GBS SNP markers. Abbreviations for country names are as per Table 1. Large font indicates the country predominantly represented in the cluster, with smaller font showing minor accessions.

sourced from global temperate pastoral systems in the Americas and Australasia (I to III in Figure 1; see Table 1 for definition of three-letter country codes). All the NZL accessions were in Cluster I. The dendrogram highlighted the small portion of diversity present in accessions from global agricultural systems (rounded rectangle), particularly New Zealand, relative to other significant sources of diversity in the Iberian Peninsula and across Europe to Central Asia. This WC study did not include cultivars and comprised only ecotypes collected from wild grasslands or mature farm systems, which gave insight into extant natural diversity. In countries where WC was introduced (i.e. NZL, AUS, USA, CAN and COS), the accessions showed alignment with potential source genetics from western Europe. Inclusion of a range of diverse cultivars in a future study will give insight into how much of the available genetic diversity, and from which origins, has been incorporated into commercial varieties.

There are few WC genetic diversity studies, and these are based on low-density marker platforms. A study of $16 \mathrm{WC}$ cultivars using 15 microsatellite (SSR) markers showed poor resolution among the cultivars (George et al. 2006), whereas a bulked AFLP analysis of 52 cultivars/ecotypes based on 197 markers discriminated between samples but was unable to align the clustering with geographic origin (Kölliker et al. 2001). The value of the bulked GBS approach in the current study is the large number of markers $(>11,000)$, which provided sufficient resolution to facilitate sample discrimination and identified differences in diversity that aligned with geographical origin. The WC accessions in this study were sampled from across its natural range spreading from western Europe to Central Asia (Daday 1958) and identified centres of diversity in the Iberian Peninsula (Cluster IV) as well as the Caucasus region and Central Asia (V). This information will drive development of a WC germplasm core collection. Extending the analysis in the future to include a range of WC cultivars and global accessions representing Northern Europe, Central Asia and Africa will give greater insight into the spread and diversity of this species, the diversity accessed in current cultivars, and provide direction for a more comprehensive core collection. 
Like WC, extensive PRG genetic diversity was identified, dispersed across eight main clusters (I-VIII in Figure 2). The majority of NZL accessions coalesced as a single compact group (VIII) and the length of the branches within the cluster indicate relatively close genetic relationships. Cluster VIII was genetically distant from three geographically aligned clusters; one associated with Italy (IV) and two associated with eastern Mediterranean, Caucasian and western Asian regions (II, III). The strong association of genetic structure with geographical origin in PRG is in agreement with other studies (Balfourier et al. 2000; Blackmore et al. 2015; Blanco-Pastor et al. 2019). Consistent with the known history of PRG introductions to New Zealand (Stewart 2006), the NZL cluster was more closely affiliated to the Iberian Peninsula (Cluster V) as well as Cluster VI. Cluster VI contains the very few accessions included in the analysis from north-western Europe and is assumed to be representative of that region. However, Cluster VI also contains accessions from numerous countries outside of north-western Europe. It is possible these are remnants from sown cultivars derived from northwestern European germplasm, the most common genetic source of modern PRG cultivars (Blanco-Pastor et al. 2019) - extension of the analysis in the future to include a wider range of north-western European ecotypes will strengthen the interpretations drawn. The most outlying group, Cluster I, consisted of accessions from a broad geographical spread and included the eight entries in the MFGC database entries noted as having a high seed awn frequency or potentially of "annual/hybrid" origin. Cluster I, therefore, most likely consists of non-PRG or PRG $x$ annual Lolium species hybrids, although substantiation of this interpretation would require close phenotypic assessment. The division of accessions from individual countries across different groups, particularly Clusters II and III, appears to be geographically influenced. For example, Greek accessions in Cluster II were sampled from the Peloponnese in the south of the country, whereas those in Cluster III were from northern regions of Greece. It is possible that these splits reflect different, prehistoric colonisation pathways for PRG (Balfourier et al. 2000).

The positioning of five NZL cultivars in the analysis reflects known breeding pedigrees and their affiliation with sub-clusters within Cluster VIII likely represent the sowing history of the sampled pastures. For cultivars bred from NZL ecotypes (Stewart 2006), 'Nui' (from the 'Mangere ecotype') and 'Samson' closely aligned in one subgroup of Cluster VIII and 'Ruanui' (from the 'Hawke's Bay ecotype') occurred in another subgroup. Interestingly, 'Impact' and 'One50' both originated from crosses between Spanish and New Zealand breeding lines and were embedded within the Iberian Peninsula cluster (V). The close association of these cultivars with Cluster V, rather than a position intermediate to Clusters V and VII, may indicate a proportionately higher Spanish genomic component in these cultivars. A small cluster (Cluster VII) of NZL accessions resolved at a position near the main NZL cluster and was associated with two Spanish accessions. All of these NZL accessions were sampled from dairy pastures in the Waikato - Bay of Plenty and it is possible that these pastures were sown with a common cultivar, presumably one with an NZL x Spanish pedigree.

In terms of coverage of the global distribution of $\mathrm{PRG}$, as in $\mathrm{WC}$, there were numerous regions either absent or under represented in the current study (north-western and central Europe, North Africa, and western and central Asia). These omissions will need to be addressed in an expansion of this research. Nevertheless, the current study highlights that, for both PRG and WC, a relatively narrow genetic basis has been deployed in pastoral agriculture in New Zealand, and that an extensive global ecotypic diversity remains largely unexploited by New Zealand breeding programmes.

\section{Conclusions/Practical implications/ Relevance}

The results of this study demonstrate that there is a relatively narrow genetic diversity amongst current New Zealand -adapted PRG and WC germplasm resources and, conversely, highlight the broad extent of largely unexploited global genetic diversity available to breeders. Extension of the GBS-based analysis to more accessions will further resolve the extent of species genetic variation and support development of manageable core collections representative of the full species diversity. Such collections can support pre-breeding programmes to mobilise novel genetic variation into New Zealand -adapted genetic backgrounds. As such, these collections will be significant genetic resources from which breeders may develop cultivars with enhanced climate resilience and environmental performance for New Zealand farmers.

\section{ACKNOWLEDGEMENTS}

This research was supported by the Ministry of Business, Innovation and Employment, New Zealand (MBIE) programme "Genomics for Production and Security in a Biological Economy", contract C10X1306 to AgResearch. We thank Jana Schmidt and Peter Moran for technical assistance.

\section{SUPPLEMENTARY MATERIAL}

Additional Online File 1: full list of the accessions selected. https://www.nzgajournal.org.nz/index.php/ JoNZG/article/view/437 


\section{REFERENCES}

Anderson CB, Franzmayr BK, Hong SW, Larking AC, van Stijn TC, Tan R, Moraga R, Faville MJ, Griffiths AG. 2018. Protocol: a versatile, inexpensive, highthroughput plant genomic DNA extraction method suitable for genotyping-by-sequencing. Plant Methods 14: 75. https://doi.org/10.1186/s13007-0180336-1

Anonymous. 2017. Pastoral Industry Discussion Document 2016 - 2036. https://beeflambnz.com/sites/ default/files/levies/files/Forage\%20Discussion $\% 20$ Document\%20November\%202017.pdf

Ashraf BH, Jensen J, Asp T, Janss LL. 2014. Association studies using family pools of outcrossing crops based on allele-frequency estimates from DNA sequencing. Theoretical and Applied Genetics 127: 1331-1341. https://doi.org/10.1007/s00122-014-2300-4

Balfourier F, Imbert C, Charmet G. 2000. Evidence for phylogeographic structure in Lolium species related to the spread of agriculture in Europe. A cpDNA study. Theoretical and Applied Genetics 101: 131138. https://doi.org/10.1007/s001220051461

Blackmore T, Thomas I, McMahon R, Powell W, Hegarty M. 2015. Genetic-geographic correlation revealed across a broad European ecotypic sample of perennial ryegrass (Lolium perenne) using arraybased SNP genotyping. Theoretical and Applied Genetics 128: 1917-1932. https://doi.org/10.1007/ s00122-015-2556-3

Blanco-Pastor JL, Manel S, Barre P, Roschanski AM, Willner E, Dehmer KJ, Hegarty M, Muylle H, Ruttink T, Roldán-Ruiz I, Ledauphin T, EscobarGutiérrez A, Sampoux J-P. 2019. Pleistocene climate changes, and not agricultural spread, accounts for range expansion and admixture in the dominant grassland species Lolium perenne L. Journal of Biogeography 46: 1451-1465. https:// doi.org/10.1111/jbi.13587

Bolaric S, Barth S, Melchinger AE, Posselt UK. 2005. Genetic diversity in European perennial ryegrass cultivars investigated with RAPD markers. Plant Breeding 124: 161-166. https://doi.org/10.1111/ j.1439-0523.2004.01032.x

Brown AHD. 1989. Core collections: a practical approach to genetic resources management. Genome 31: 818-824. https://doi.org/10.1139/g89-144

Byrne S, Czaban A, Studer B, Panitz F, Bendixen C, Asp T. 2013. Genome wide allele frequency fingerprints (GWAFFs) of populations via genotyping by sequencing. PLOS ONE 8: e57438. https://doi. org/10.1371/journal.pone.0057438

Catchen J, Hohenlohe PA, Bassham S, Amores A, Cresko WA. 2013. Stacks: an analysis tool set for population genomics. Molecular Ecology 22: 31243140. https://doi.org/10.1111/mec.12354
Chapman DF, Bryant JR, Olayemi ME, Edwards GR, Thorrold BS, McMillan WH, Kerr GA, Judson G, Cookson T, Moorhead A, Norriss M. 2017. An economically based evaluation index for perennial and short-term ryegrasses in New Zealand dairy farm systems. Grass and Forage Science 72: 1-21. https:// doi.org/10.1111/gfs.12213

Daday H. 1958. Gene frequencies in wild populations of Trifolium repens L. III. World distribution. Heredity 12: 169-184. https://doi.org/10.1038/hdy.1958.22

Dodds KG, McEwan JC, Brauning R, Anderson RM, van Stijn TC, Kristjánsson T, Clarke SM. 2015. Construction of relatedness matrices using genotyping-by-sequencing data. BMC Genomics 16: 1047. https://doi.org/10.1186/s12864-015-2252-3

Easton HS, Latch GCM, Tapper BA, Ball OJ-P. 2002. Ryegrass host genetic control of concentrations of endophyte-derived alkaloids. Crop Science 42: 5157. https://doi.org/10.2135/cropsci2002.5100

Elshire RJ, Glaubitz JC, Sun Q, Poland JA, Kawamoto K, Buckler ES, Mitchell SE. 2011. A robust, simple Genotyping-by-Sequencing (GBS) approach for high diversity species. PLOS ONE 6: e19379. https://doi. org/10.1371/journal.pone.0019379

Faville MJ, Ganesh S, Cao M, Jahufer MZZ, Bilton TP, Easton HS, Ryan DL, Trethewey JAK, Rolston MP, Griffiths AG, Moraga R, Flay C, Schmidt J, Tan R, Barrett BA. 2018. Predictive ability of genomic selection models in a multi-population perennial ryegrass training set using genotyping-bysequencing. Theoretical and Applied Genetics 131: 703-720. https://doi.org/10.1007/s00122-017-3030-1

Faville MJ, Crush JR, Hong W, Phillips H, Lee JM, Chapman D. 2020. Effects of pasture age on the genotype and phenotype of perennial ryegrass. Grass and Forage Science 75: 135-144. https://doi. org $/ 10.1111 / \mathrm{gfs} .12474$

Ford JL, Barrett BA. 2011. Improving red clover persistence under grazing. Proceedings of the New Zealand Grassland Association 61: 119-124. https:// doi.org/10.33584/jnzg.2011.73.2838

Frankel OH. 1984. Genetic perspectives of germplasm conservation. In: Arber W, Llimensee K, Peacock WJ, Starlinger R Ed. Genetic manipulation: Impact on man and society, pp. 161-170. Cambridge, UK: Cambridge University Press.

George J, Dobrowolski MP, van Zijll de Jong E, Cogan NOI, Smith KF, Forster JW. 2006. Assessment of genetic diversity in cultivars of white clover (Trifolium repens L.) detected by SSR polymorphisms. Genome 49: 919-930. https://doi.org/10.1139/g06-079

Ghamkhar K, Snowball R, Wintle BJ, Brown AHD. 2008. Strategies for developing a core collection of bladder clover (Trifolium spumosum L.) using ecological and agro-morphological data. Australian 
Journal of Agricultural Research 59: 1103-1112. https://doi.org/10.1071/AR08209

Glaubitz JC, Casstevens TM, Lu F, Harriman J, Elshire RJ, Sun Q, Buckler ES. 2014. TASSEL-GBS: A high capacity genotyping by sequencing analysis pipeline. PLOS ONE 9: e90346. https://doi.org/10.1371/ journal.pone. 0090346

Gouesnard B, Bataillon TM, Decoux G, Rozale C, Schoen DJ, David JL. 2001. MSTRAT: An algorithm for building germplasm core collections by maximizing allelic or phenotypic richness. Journal of Heredity 92: 93-94. https://doi.org/10.1093/ jhered/92.1.93

Griffiths AG, Moraga R, Tausen M, Gupta V, Bilton TP, Campbell MA, Ashby R, Nagy I, Khan A, Larking A, Anderson C, Franzmayr B, Hancock K, Scott A, Ellison NW, Cox MP, Asp T, Mailund T, Schierup MH, Andersen SU. 2019. Breaking free: The genomics of allopolyploidy-facilitated niche expansion in white clover. The Plant Cell 31: 14661487. https://doi.org/10.1105/tpc.18.00606

Harmer M, Stewart AV, Woodfield DR. 2016. Genetic gain in perennial ryegrass forage yield in Australia and New Zealand. Journal of New Zealand Grasslands 78: 133-138. https://doi.org/10.33584/ jnzg.2016.78.514

Hoyos-Villegas V, O'Connor JR, Heslop AD, Hilditch A, Jahufer MZZ, Barrett BA. 2019. Rate of genetic gain for persistence to grazing and dry matter yield in white clover across 90 years of cultivar development. Crop Science 59: 537-552. https://doi.org/10.2135/ cropsci2018.07.0471

Humphreys MO. 1989. Water-soluble carbohydrates in perennial ryegrass breeding. I. Genetic differences among cultivars and hybrid progeny grown as spaced plants. Grass and Forage Science 44: 231-236. https://doi.org/10.1111/j.1365-2494.1989.tb01931.x

Khanlou KM, Vandepitte K, Asl LK, Bockstaele EV. 2011. Towards an optimal sampling strategy for assessing genetic variation within and among white clover (Trifolium repens L.) cultivars using AFLP. Genetics and Molecular Biology 34: 252-258. https:// doi.org/10.1590/S1415-47572011000200015

Kölliker R, Jones ES, Jahufer MZZ, Forster JW. 2001. Bulked AFLP analysis for the assessment of genetic diversity in white clover (Trifolium repens L.). Euphytica 121: 305-315. https://doi. org/10.1023/A:1012048103585

Kubik C, Sawkins M, Meyer WA, Gaut BS. 2001. Genetic diversity in seven perennial ryegrass (Lolium perenne L.) cultivars based on SSR markers. Crop Science 41: 1565-1572. https://doi.org/10.2135/ cropsci2001.4151565x
Lee JM, Matthew C, Thom ER, Chapman DF. 2012. Perennial ryegrass breeding in New Zealand: a dairy industry perspective. Crop and Pasture Science 63: 107-127. https://doi.org/10.1071/CP11282

Ministry for Primary Industries. 2016. How valuable is that plant species? Application of a method for enumerating the contribution of selected plant species to New Zealand's GDP. Wellington, New Zealand, 212 p. https://www.biosecurity.govt.nz/ dmsdocument/14527/direct

Ministry for Primary Industries. 2017. Primary Sector Science Roadmap: Te Ao Türoa. Wellington, New Zealand, 57 p. https://www.mpi.govt.nz/ dmsdocument/18383-primary-sector-scienceroadmap-te-ao-turoa-strengthening-new-zealandsbioeconomy-for-future-generations

Paradis E, Schliep K. 2018. ape 5.0: an environment for modern phylogenetics and evolutionary analyses in R. Bioinformatics 35: 526-528. https://doi. org/10.1093/bioinformatics/bty633

Poland JA, Brown PJ, Sorrells ME, Jannink J-L. 2012. Development of high-density genetic maps for barley and wheat using a novel two-enzyme genotyping-bysequencing approach. PloS ONE 7: e32253-e32253. https://doi.org/10.1371/journal.pone.0032253

Stewart AV. 2006. Genetic origins of perennial ryegrass (Lolium perenne) for New Zealand pastures. In: Mercer CF Ed. Breeding for Success: Diversity in Action. Proceedings of the 13th Australasian Plant Breeding Conference, Christchurch, New Zealand, 18-21 April, pp. 11-20. Published in: Advances in Plant Breeding. Research and Practice Series No. 12. pp. 55-61. New Zealand Grassland Association. https://www.nzgajournal.org.nz/index.php/rps/ article/view/3042

Widdup KH, Woodfield DR, Baird IJ, Clifford PTP. 2004. Response to selection for seed yield in six white clover cultivars. Proceedings of the New Zealand Grassland Association 66: 103-110. https:// doi.org/10.33584/jnzg.2004.66.2566

Williams WM, Easton HS, Jones CS. 2007. Future options and targets for pasture plant breeding in New Zealand. New Zealand Journal of Agricultural Research 50: 223-248. https://doi. org/10.1080/00288230709510292

Woodfield DR, Caradus JR. 1987. Adaptation of white clover to water stress. Proceedings of the New Zealand Grassland Association 48: 143-149. https:// doi.org/10.33584/jnzg.1987.48.1798

Woodfield DR, Easton HS. 2004. Advances in pasture plant breeding for animal productivity and health. New Zealand Veterinary Journal 52: 300-310. https:// doi.org/10.1080/00480169.2004.36446 